\title{
INOVASI PENINGKATAN HASIL TANGKAPAN IKAN PRODUK UNGGULAN DAERAH OLEH NELAYAN PURSE SEINE MENGGUNAKAN TEKNOLOGI GPS
}

\author{
Zaenal Arifin'1, Buang Budi Wahono², Dias Prihatmoko 3 , Sisno Riyoko 4 \\ ${ }^{1}$ Teknik Elektro, Universitas Islam Nahdlatul Ulama Jepara \\ korespondensi email: zaenalarifin210689@gmail.com \\ ${ }^{2}$ Teknik Informatika, Universitas Islam Nahdlatul Ulama Jepara \\ email: budihono78@gmail.com \\ ${ }^{3}$ Teknik Elektro, Universitas Islam Nahdlatul Ulama Jepara \\ email: thaka_air@yahoo.com \\ ${ }^{4}$ Teknik Industri, Universitas Islam Nahdlatul Ulama Jepara \\ email: riyoko.lppm@gmail.com
}

\begin{abstract}
Livelihoods as fishermen are the backbone for people who live near the coast, it is not much different from the people in Jobokuto village, Jepara Regency who also work as fishermen, so far the catches of fishermen after getting catches of fish are directly sold to middlemen or local fish auction sites, so that fishermen cannot increase fish catches to be processed into commodities that have high economic value so that their economy can increase. Based on this description, service activities are carried out to fishermen by providing training ranging from the potential of fisheries, the superiority of GPS and Sounder technology, increased catches on processed fish and stabilization of processed fish equipment ranging from fish shredder, shredded cooker, shredded slicer, bender, spinner as well as tools fish smoke. Some of these activities are expected to result in the end that fishermen SMEs can develop their businesses, increase catches and sales, and improve the welfare of fishermen in Jepara Regency. The activity is also expected to be a pilot project for other fishermen in the district in implementing fishing technology using a fish finder with the use of appropriate technology that is environmentally friendly.
\end{abstract}

Keywords: fishermen; GPS; sounder

\begin{abstract}
ABSTRAK
Mata pencaharian sebagai nelayan merupakan tulang punggung bagi masyarakat yang hidup disekitar pesisir daerah pantai, hal itu tidak jauh berbeda dengan masyarakat di desa Jobokuto Kabupaten Jepara yang juga berprofesi sebagai nelayan, selama ini hasil tangkapan para nelayan setelah mendapatkan hasil tangkapan ikan langsung dijual kepada tengkulak atau tempat pelelangan ikan setempat, sehingga nelayan tidak bisa meningkatkan hasil tangkapan ikan untuk diolah menjadi komoditas yang memiliki nilai ekonomis tinggi sehingga perekonomian mereka dapat meningkat. Berdasarkan gambaran tersebut dilaksanakanlah kegiatan pengabdian kepada nelayan dengan pemberian training mulai dari potensi perikanan, keunggulan teknologi GPS dan Sounder, peningkatan hasil tangkapan pada olahan ikan serta pemantapan alat olahan ikan mulai dari alat pencabik ikan, pemasak abon, peniris abon, bender, spinner juga
\end{abstract}


alat asap ikan. Beberapa kegiatan tersebut diharapkan hasil akhirnya adalah UKM nelayan dapat mengembangkan usahanya, meningkatkan hasil tangkapan dan penjualan, serta meningkatkan kesejahteraan nelayan dikabupaten Jepara. Kegiatan tersebut juga diharapkan dapat menjadi pilot project untuk nelayan lainnya dikabupaten dalam menerapkan teknologi penangkapan ikan menggunakan fish finder dengan pemanfaatan teknologi tepat guna yang ramah lingkungan.

Kata Kunci: nelayan; GPS; sounder

\section{PENDAHULUAN}

Sumberdaya ikan yang hidup di wilayah perairan Indonesia dinilai memiliki tingkat keragaman hayati (bio-diversity) yang paling tinggi. Sumberdaya tersebut paling tidak mencakup 37\% dari spesies ikan di dunia (Kantor Menteri Negara Lingkungan Hidup, 1994). Di wilayah perairan laut Indonesia memiliki beberapa jenis ikan dengan nilai ekonomis tinggi antara lain : tuna, cakalang, udang, tongkol, tenggiri, kakap, cumi-cumi, ikan-ikan karang (kerapu, baronang, udang barong/lobster), ikan hias dan jenis-jenis kerang termasuk rumput laut (Barani, 2004).

Jepara adalah salah satu kabupaten yang berada di pantai utara jawa, Jepara merupakan wilayah dekat pantai yang memiliki garis pantai sepanjang $72 \mathrm{~km}$, memiliki potensi dalam bidang perikanan sangat besar. Dengan garis pantai sepanjang $72 \mathrm{~km}$ termasuk keberadaan Karimunjawa, maka luas wilayah penangkapan laut, baik jalur I, II dan III mencapai 1.500 km2. Sedangkan budidaya laut dapat dilakukan di atas areal seluas $10.000 \mathrm{Ha}$ dan luas areal budi daya laut dan penangkapan diperairan umum mencapai $1.472 \mathrm{Ha}$ lebih. Banyaknya jumlah sumber daya manusia di jepara yang berprofesi menjadi nelayan menandakan bahwa sumber perikanan di pantai jepara sangat melimpah.

Mitra Purihuna adalah satu diantara sekian ribu nelayan yang ada di kabupaten jepara. Mitra Purihuna yang di pimpin oleh bapak $\mathrm{H}$. Soka mempunyai karyawan sebanyak 30 nelayan, mempunyai 2 kapal penangkap ikan dengan peralatan tangkap ikan masih tradisional. Saat menangkap ikan dilaut, mitra menggunakan rata-rata kapal mini purse seine dengan peralatan tangkap sederhana yaitu menggunakan peralatan manual dan jaring yang mengandalkan histori koordinat sesuai catatan dan penggunaan rumpon sebagai pemancing ikan agar mendekat baru kemudian ikan ditangkap menggunakan jaring purse seine. Kelemahan sistem tradisional ini adalah terjadi pemborosan baik pada bahan bakar, waktu, biaya opersional dan hasil tangkapan ikan yang tidak menentu.

Biaya operasional KM Purihuna sekali melaut harian adalah 3 juta dan yang mingguan 40 Juta. Dengan biaya operasional yang begitu besar maka nelayan dituntut supaya mendapatkan ikan sebanyak-banyaknya untuk menutup biaya operasional tersebut. Selanjutnya dalam hal menentukan lokasi penangkapan ikan, proses yang selama ini berjalan adalah nelayan asal menjalankan perahunya ke tengah laut dengan sistem tradisional, yaitu dengan cara melihat tanda-tanda alam. Jika lokasi tersebut diatasnya ada burung maka 
lokasi tersebut pertanda banyak ikannya, tanda lainnya adalah dengan melihat jika ada ikan meloncat-loncat di permukaan laut pertanda lokasi tersebutbanyak ikannya juga. Sistem seperti ini juga mempunyai kelemahan bahwa pertanda tersebut diatas belum tentu lokasinya banyak ikannya. Hal ini menjadikan perjalanan sia-sia dan pemborosan bahan bakar. Hal ini jika dilalui terus menerus maka akan memberatkan mitra tersebut.

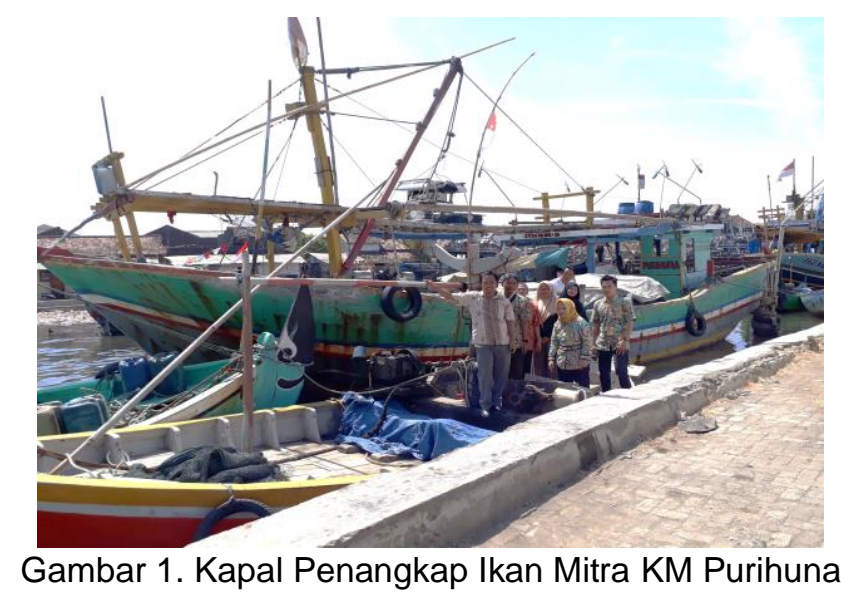

Beberapa jenis ikan yang biasa ditangkap oleh mitra diantaranya yaitu ikan kakap, ikan kembung, ikan selar, ikan tongkol, ikan tengiri dan ikan badong. Ikan-ikan hasil tangkapan tersebut biasanya dijual kepada tengkulak untuk selanjutnya di jual ke tempat pelelangan ikan (TPI) di kabupaten Jepara. Terkadang jika masa-masa musim sepi ikan maka nelayan bisa saja merugi karena biaya operasional lebih tinggi daripada hasil tangkapannya.

Berdasarkan kelemahan tersebut, solusi yang diambil diantaranya yaitu: (1). Pengarahan pentingnya paguyuban antar nelayan, (2). Strategi mencari pinjaman modal ke bank dan mengurangi hutang ke tengkulak, (3). Workshop manajemen, (4). Menjalin hubungan dengan lembaga finansial, (5). Workshop penerapan teknologi penangkapan ikan menggunakan sounder dan fish finder (6). Workshop Pengolahan Ikan (7). Workshop penjualan online. Sehingga kelemahan yang ada bisa teratasi melalui solusi tersebut, untuk meningkatkan hasil tangkapan ikan dan perekonomian nelayan.

\section{METODE PELAKSANAAN}

Pelaksanaan kegiatan yang dilakukan oleh tim PPPUD UNISNU Jepara, dimana PPPUD merupakan singkatan dari Program Pengembangan Produk Unggulan Daerah yang dilakukan oleh dosen suatu Universitas yang dibiayai oleh hibah multi tahun dari Kementrian Riset dan Teknologi Perguruan Tinggi Indonesia, dengan mitra nelayan di Kabupaten Jepara pada tahun 2018 - 2020. Permasalahan yang muncul pada mitra akan diselesaikan secara bertahap. Berikut metode pelaksanaan dari program PPPUD UNISNU Jepara. 
a. Daerah Penangkapan Ikan

Menerapkan GPS berupa peta daerah penangkapan ikan berdasarkan komunitas untuk membantu nelayan menemukan lokasi penangkapan ikan.

b. Penangkapan Ikan

Meningkatkan teknologi penangkapan ikan dari cara manual dengan gejala alam ke fish finder.

c. Proses

Membuat Layout dan Membuat Standar Mutu mulai dari proses penangkapan ikan sampai ke penjualan.

Berdasarkan uraian penyelesaian permasalahan diatas faktor yang dijadikan tolok ukur adalah sebagai berikut:

a. Jumlah dan mutu hasil tangkapan ikan sekarang meningkat menjadi 2 sampai 5 kali lipat dibandingkan menggunakan cara tradisional,

b. Memperluas pemasaran, yaitu dengan menciptakan kreasi hasil tangkapan olahan ikan berupa abon ikan

c. Adanya paguyuban nelayan yaitu KUB Selera Jepara di desa Jobokuto.

d. Meningkatkan kerja sama dengan mitra financial perbankan dan paguyuban nelayan sekitar.

\section{Permasalahan Mitra}

Hasil analisis situasi dari mitra nelayan purse seine di kabupaten jepara mempunyai permasalahan yang hampir sama antara lain: manajemen, teknologi penangkapan, pemasaran dan permodalan. Berikut uraian dari Permasalahan Mitra:

a. Daerah Penangkapan Ikan. Nelayan dalam menemukan daerah penangkapan ikan dengan menggunakan teknik manual yaitu dengan melihat apakah ada ikan yang meloncat-loncat di permukaan dan juga dengan melihat apakah ada burung diatas air atau tidak.

b. Penangkapan Ikan. Dalam menangkap ikan masih dikerjakan secara manual dengan menggunakan Fish Finder dengan daya yang besar dan jaring, serta kurangnya teknologi penangkapan yang lebih baik. Sehingga biaya operasional tinggi.

c. Proses. untuk lay out sudah sesuai alur penangkapan, tidak mempunyai jaminan mutu hasil penangkapan.

d. Manajemen. Menggunakan manajemen keluarga. Belum mempunyai manajemen yang standart diantaranya: (production,planning, accounting,bookkeeping, auditing dan Inventory).

e. Distribusi. Dijual ke TPI dan Diambil oleh tengkulak.

f. Pemasaran. Belum memanfaatkan website, ikan dijual ke TPI dan tengkulak, teknik produksi manual, harga jual mengikuti harga yang dibuat oleh tengkulak.

g. SDM. Rata-rata lulusan SMP dan SMA. 
h. Sarana. Kapal penangkap ikan berupa kapal sekala kecil dengan peralatan sederhana berupa jaring dan Fish Finder.

i. Finansial. Modal dari Bank.

\section{Solusi dan Target}

Berdasarkan permasalahan yang muncul akan dicari solusi dalam penyelesaian permasalahannya, antara lain:

a. Menerapkan aplikasi mobile peta daerah penangkapan ikan secara online berdasarkan komunitas nelayan, sistem dilengkapi dengan GPS untuk mengetahui posisi terakhir nelayan secara online, kemudian posisi tersebut akan menjadi referensi bagi nelayan lainnya bahwa posisi tersebut ada ikannya atau tidak. Sistem juga diintegrasikan dengan sistem peta yang ada di kementrian kelautan dan perikanan (https://kkp.go.id).

b. Menerapkan peralatan perikanan Sounder dan Fish Finder yang lebih hemat energi dan ramah lingkungan.

c. Mengadakan pengarahan dan workshop manajemen serta pentingnya paguyuban dengan nelayan.

d. Training / Workshop pengembangan sumber daya manusia UKM mitra untuk meningkatkan kompetensi mitra.

e. Training hasil tangkapan olahan ikan berupa abon ikan kepada KUB Selera Jepara.

f. Memperluas pemasaran hasil kreasi olahan ikan baik di gerai - gerai makanan dan di media sosial.

Perlu adanya workshop teknik pemasaran yang baru salah satunya dengan penjualan online yang bisa diakses umum untuk mengembangkan unit usaha nya ke luar kabupaten jepara.

\section{HASIL DAN PEMBAHASAN}

Pada pelaksanaan program hibah ini, tim melakukan beberapa training kepada mitra KM Purihuna untuk meningkatkan kemampuan baik soft skill dan SDM, sehingga mitra mendapatkan pengetahuan dan kemampuan lebih untuk meningkatkan hasil tangkapan ikan yang selama ini mereka jadikan sebagai mata pencaharian utama masyarakat nelayan di pesisir sekitar pantai, terutama masyarakat di desa Jobokuto Jepara. Beberapa training yang diberikan kepada mitra adalah sebagai berikut:

1. Training Potensi Perikanan Di Laut Jepara Tahap 1

Training ini memaparkan tentang potensi perikanan di laut Jepara kepada nelayan yang bisa dimanfaatkan sebagai pengetahuan akan besarnya potensi ikan yang berada di sekitar laut Jepara, sehingga nelayan tidak khawatir akan kekurangan ikan dan mengetahui potensi ikan di lautan Jepara, dengan training ini nelayan sekarang mengetahui banyaknya potensi daerah tangkapan ikan di lautan Jepara. 
2. Training Potensi Perikanan Di Laut Jepara Tahap 2

Training ini memaparkan tentang teknik-teknik yang digunakan nelayan dalam menangkap jenis-jenis ikan yang bisa dimanfaatkan sebagai pengetahuan dalam menangkap ikan yang berada di sekitar laut Jepara, sehingga nelayan mendapat pengetahuan dan kemampuan lebih dalam teknik penangkapan ikan yang efektif, dengan training ini nelayan sekarang mengetahui banyaknya potensi jenis ikan di lautan Jepara.

3. Training Keunggulan Teknologi GPS dan Sounder

Training ini memaparkan tentang keunggulan teknologi GPS dan Sounder kepada nelayan yang bisa dimanfaatkan untuk mengetahui lokasi koordinat keberadaan ikan di dalam laut. Manfaat yang dirasakan nelayan dari training ini adalah efisiensi kapal nelayan saat berlabuh dapat langsung menuju ke koordinat keberadaan ikan yang dituju dan mengurangi biaya hidup dan BBM kapal selama berlabuh di lautan yang menjadikan lebih efektif dan efisien dari sisi pengeluaran biaya akomodasi dan hasil tangkapan ikan meningkat menjadi 2 sampai 5 kali lipat dari sebelumnya.

4. Training Peningkatan Hasil Tangkapan Pada Olahan Ikan

Training ini memaparkan tentang peningkatan hasil tangkapan pada olahan ikan kepada nelayan yang bisa dimanfaatkan kepada hasil yang bernilai ekonomi lebih, sehingga pendapatan perekonomian mereka bisa meningkat, salah satunya yaitu pembuatan abon ikan yang sudah diapsarkan di gerai-gerai makanan dan penjualan di media sosial dengan nama KUB Selera Jepara.

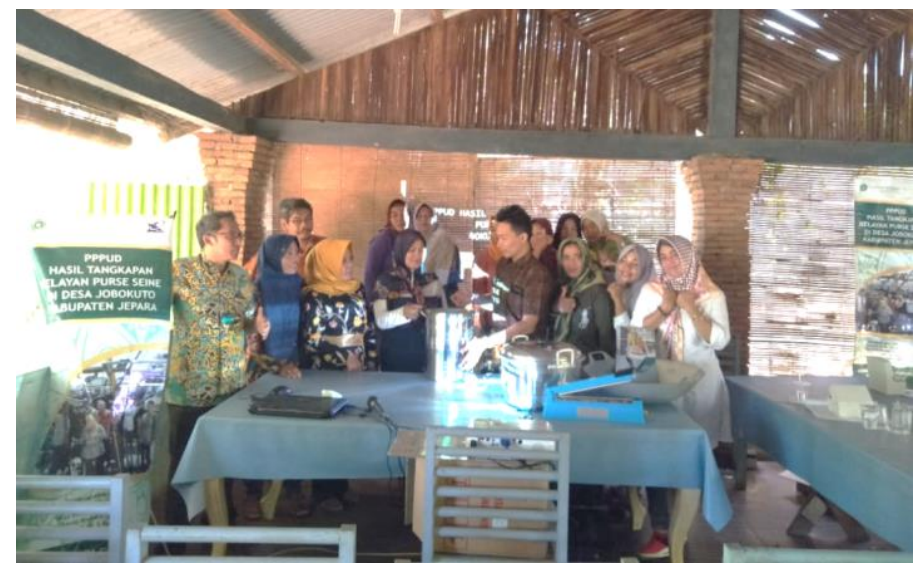

Gambar 2. Pelatihan pembuatan abon ikan

Dukungan yang dibutuhkan dalam pelaksanaan program hibah ini, tim melakukan beberapa pemantapan alat untuk mendukung kegiatan pengabdian kepada mitra ini, sehingga nelayan bisa membuat kreasi hasil olahan ikan menjadi produk yang lebih bernilai ekonomis, diantaranya adalah: 
1. Alat Pendeteksi Keberadaan Ikan

Alat ini berupa GPS dan Sounder Garmin untuk mendeteksi keberadaan ikan di laut sampai kedalaman 800 meter dibawah permukaan laut.

2. Alat Pencabik Daging dan Ikan

Alat ini difungsikan sebagai pencabik daging dan ikan, yang bisa dimanfaatkan sebagai daging dan ikan menghasilkan tekstur yang lebih kecil.

3. Alat Pemasak Abon

Alat ini difungsikan sebagai pemasak abon ikan, yang bisa dimanfaatkan sebagai pembuatan abon dari bahan dasar ikan.

4. Alat Peniris Abon

Alat ini difungsikan sebagai peniris abon ikan, yang bisa dimanfaatkan sebagai peniris minyak pada pembuatan abon ikan.

5. Alat Blender dan Spinner

Alat ini difungsikan sebagai blender dan spinner ikan, yang bisa dimanfaatkan sebagai pelumat dan menghilangkan kadar air yang ada pada ikan sehingga menghasilkan tekstur ikan yang halus.

6. Alat Asap Ikan

Alat ini difungsikan sebagai pengasap ikan, yang bisa dimanfaatkan sebagai pengurang kadar air ikan, terlebih dimusim hujan yang jarang terkena sinar matahari, sehingga ikan bisa diawetkan dan tidak cepat membusuk.

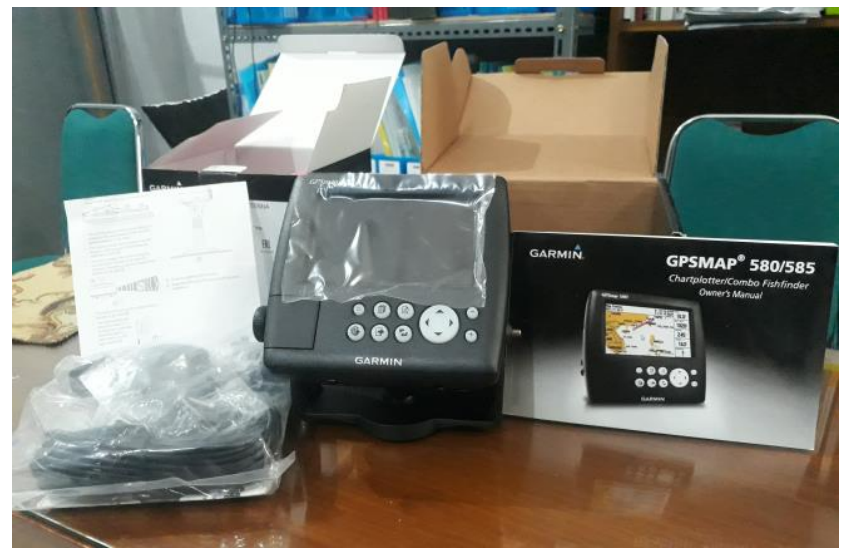

Gambar 3. Alat GPS dan Sounder Garmin

\section{KESIMPULAN}

Berdasarkan hasil kegiatan yang sudah dilaksanakan oleh tim, maka didapatkan hasil kesimpulan antara lain: (1) Pemanfaatan yang dilakukan nelayan dengan menggunakan keunggulan teknologi GPS dan Sounder, memberikan dampak positif terhadap peningkatan hasil tangkapan ikan nelayan purse seine sebesar 2 sampai 5 kali lipat dari tangkapan ikan semula yang hanya 1 ton, (2) Hasil tangkapan ikan yang diperoleh, sebagian dapat 
dimanfaatkan pada olahan ikan dengan mengkreasikan menjadi prosuk abon ikan dengan merk Selera Jepara, yang diapasaran di gerai-gerai makanan dan promosi di media sosial, (3) Solusi yang tepat untuk memfasilitasi peningkatan hasil tangkapan ikan nelayan purse seine, yaitu melalui pelatihan dan pemanfaatan teknologi tepat guna (GPS dan Sounder) serta peningkatan nilai ekonomis produk hasil olahan ikan berupa abon ikan, dan (4) Program yang diajalankan oleh tim pengabdi memberikan hasil positif dan ketercapaian program sebesar $90 \%$.

Berdasarkan hasil kegiatan yang sudah dilaksanakan, maka tim pelaksana menyarankan bahwa untuk menindaklanjuti kegiatan ini diperlukan:

1. Pendampingan dan pelatihan lanjutan yang lebih mendalam kepada mitra baik dari sisi pemanfatan dan penggunaan peralatan teknologi.

2. Pendampingan dan pelatihan lanjutan untuk mencipatakan kreasi tambahan olahan hasil tangkapan ikan.

3. pendampingan dan pelatihan lanjutan dari sisi promosi dan pemasaran produk, agar semakin dikenal masyarakat.

\section{DAFTAR RUJUKAN}

Andriani, L.A. dan Ayunita, D. 2012. Potensi dan Tingkat Pemanfaatan Sumberdaya Ikan Demersal di Perairan Kabupaten Pekalongan. Jurnal Agriekonomika. Trunojoyo. 1(1).

Ernawati, T dan Sumiono, B. 2009. Fluktuasi Bulanan Hasil Tangkapan Cantrang Yang Berbasis Di Pelabuhan Perikanan Pantai Tegal Sari, Kota Tegal. J. Lit. Perikan. Ind. 15 (1)

Gugik Gustaman, dkk, 2012. Efektifitas Perbedaan Warna Cahaya Fish Finder terhadap Hasil Tangkapan Bagan Tancap di Perairan Sungsang Sumatera Selatan. Maspari Journal, 2012, 4(1), 92-102

Hiariey, L. S dan Romeon, N. R. 2013. Peran Serta Masyarakat Pemanfaat Pesisir dalam Pengelolaan Wilayah Pesisir Teluk Ambon Dalam. Jurnal Matematika, Sains, dan Teknologi. 14 (1) : 48-61

Ika Ruhana, Pengembangan Kualitas Sumber Daya Manusia Vs Daya Saing Global, Jurnal Profit, Volume 6, Nomor 1, Juni 2012.

Jamal, M., Sondita, F.A, Wiryawan, B dan Haluan, j. 2014. Konsep Pengelolaan Perikanan Tangkap Cakalang (Katsuwonus pelamis) dl Kawasan Teluk Bone Dalam Perspektif Keberlanjutan. Jurnal IPTEKS PSP. 1 (2) : 196207

Kamaludin dan Rini Indriani, 2012 Manajemen Keuangan Edisi Revisi Konsep Dasar dan Penerapannya. Cetakan ke II. CV Mandar Maju. Bandung

Kementerian Kelautan dan Perikanan. 2013. Profil Kelautan dan Perikanan Provinsi Jawa Tengah. Jakarta Peraturan Menteri Kelautan dan Perikanan Nomor 2 Tahun 2015 
Muhammad Fauzi, dkk. 2014. Profil Sumber Daya Perikanan Pada Wilayah Pengelolaan Kawasan Konservasi Laut Daerah (Kkld) Kabupaten Lingga. Prosiding Seminar Antar Bangsa Ke 5. University Of Riau. Riau Peraturan Menteri Kelautan Dan Perikanan Republik Indonesia Nomor 2/Permen-Kp/2015 tentang Larangan Penggunaan Alat Penangkapan Ikan Pukat Hela Dan Pukat Tarik Di Wilayah Pengelolaan Perikanan Negara Republik Indonesia

Peraturan Menteri Kelautan Dan Perikanan Republik Indonesia Nomor 71/Permen-Kp/2016 Tentang Jalur Penangkapan Ikan Dan Penempatan Alat Penangkapan Ikan Di Wilayah Pengelolaan Perikanan Negara Republik Indonesia

Vibriyanti, D. 2014. Kondisi Sosial Ekonomi dan Pemberdayaan Nelayan Tangkap Kota Tegal, Jawa Tengah. Jurnal Kependudukan Indonesia. 9 (1)

Wiyono, E.S. 2010. Komposisi, Diversitas dan Produktivitas Sumberdaya Ikan Dasar di Perairan Pantai Cirebon, Jawa Barat. IImu Kelautan. 15 (4) 214-220 